\title{
Efecto Antagónico del Kefir sobre Endosporas y Células Vegetativas de Bacillus Cereus y Clostridium Perfringens
}

\author{
Ricardo J. Anselmo ${ }^{(1)^{*}}$, Silvia S. Viora ${ }^{(1)}$, Pablo A. Ojeda ${ }^{(1)}$, Lucía I. Lausada $^{(2)}$ \\ Univ. Nacional de Luján, (1) Depto. de Ciencias Básicas, (2) Depto. de Tecnología, Casilla 221, \\ (6700) Luján, Buenos Aires-Argentina (e-mail: anselmoricardoj@msn.com)
}

* autor a quien debe ser dirigida la correspondencia

Recibido Oct. 19, 2009; Aceptado Nov. 24, 2009; Versión Final recibida Dic. 01, 2009

\begin{abstract}
Resumen
Se estudió el efecto bactericida del kéfir sobre endosporas y células vegetativas de Bacillus cereus y Clostridium perfringens inoculados en kéfir durante su almacenamiento. Muestras de kéfir de dos procedencias, uno de origen italiano y otro peruano, fueron inoculadas con una población conocida de $B$. cereus y $\mathrm{Cl}$. perfringens $\left(10^{6} \mathrm{UFC} / \mathrm{mL}\right)$ y conservados a $4^{\circ} \mathrm{C}$ durante 30 días. Cada dos días se realizó un recuento de bacterias lácticas, de levaduras, de los patógenos agregados y se determinó el $\mathrm{pH}$. La población de células vegetativas de $B$. cereus se redujo a niveles no detectables en 14 días de almacenamiento y la de sus endosporas en 20 días de almacenamiento. Respecto a $\mathrm{Cl}$. perfringens se redujo la población de células vegetativas y de endosporas a niveles no detectables en 14 y 18 días de almacenamiento, respectivamente. Los resultados confirman los efectos bactericidas de los cultivos iniciadores del kéfir.
\end{abstract}

Palabras clave: kéfir, Bacillus cereus, Clostridium perfringens, efecto bactericida

\section{Antagonistic Effect of the Kefir on Endospores and Vegetative Cells of Bacillus Cereus and Clostridium Perfringens}

\begin{abstract}
The bactericide effect of the kefir was studied on endospores and vegetative cells of Bacillus cereus and Clostridium perfringens inoculated in kefir during its storage. Samples of kefir of two different origins, one Italian and the other Peruvian were inoculated with a well-known population of $B$. cereus and $\mathrm{Cl}$. perfringens $\left(10^{6} \mathrm{UFC} / \mathrm{mL}\right)$ and conserved at $4^{\circ} \mathrm{C}$ during 30 days. Every two days it was carried out a recount of lactic bacteria, of yeasts, of the pathogenic added and the $\mathrm{pH}$ was determined. The population of vegetative cells of $B$. cereus reduced to non detectable levels in 14 days of storage and of its endospores in 20 days of storage. Regarding $\mathrm{Cl}$. perfringens the population of vegetative cells and its endospores reduced to non detectable levels in 14 and 18 days of storage, respectively. The results confirm the bactericide effects of the starter cultures of kefir.
\end{abstract}

Keywords: Kefir, Bacillus cereus, Clostridium perfringens, bactericide effect 


\section{INTRODUCCIÓN}

El kéfir es una bebida láctea fermentada naturalmente carbonatada con un sabor ligeramente ácido, a levadura y de consistencia cremosa. Cuando se agita, la bebida produce espuma y efervescencia, característica por la que se le ha denominado la champaña de los productos lácteos cultivados (Tamime et al., 1999).

La fermentación comienza mediante la adición de granos de kéfir a leche fresca. Los granos son insolubles en agua y de tamaño y forma irregular, variando de 0,3-3,5 cm de diámetro. Se ha demostrado en la literatura (Powell et al., 2007) que cuando se suspenden en leche, los granos se hinchan para formar un producto gelatinoso conocido como kefiran, un polisacárido compuesto por glucosa y galactosa en idénticas proporciones. Una gran variedad de especies de microorganismos han sido aislados e identificados de los granos de kéfir, tales como Lactobacillus, Lactococcus, Acetobacter y levaduras. El kefiran es producido en el centro de los granos, sintetizado principalmente por Lactobacillus kefiranofaciens. La composición microbiana del kéfir está determinada por la fuente de los granos, el proceso de fermentación y las condiciones de almacenamiento. Tambièn se han descrito hongos filamentosos, pero están presentes en números bajos.

La actividad antimicrobiana del kéfir se atribuye al ácido láctico, ácido acético, peróxido de hidrógeno, dióxido de carbono, diacetilo, acetaldehído, y/o bacteriocinas producidas por Lactobacillus (Havenaar et al., 1992; Helander et al., 1997). Golowczyc et al. (2004) establecieron que los sobrenadantes de lactobacilos homofermentativos ejercerían una acción bactericida sobre Salmonella lo cual estaría asociado al bajo pH de los mismos. Kakisu et al. (2004) hallaron que el kéfir inhibiría la germinación de endosporas de Bacillus cereus y, si los gránulos de kéfir se hallaran contaminados con endosporas de este patógeno, paulatinamente irían perdiendo dicha contaminación hasta desaparecer a través de los sucesivos repiques en leche no contaminada.

Se ha demostrado en la literatura (Rodrigues et al., 2005) que el kéfir inhibió el crecimiento de Streptococcus pyogenes y Candida albicans". En otro estudio, cepas de Lactococcus lactis subsp. lactis, $L$. lactis subsp. cremoris y $L$. thermophylus, aislados de kéfir inhibieron el crecimiento de $S$. aureus. Además, dos cepas $L$. lactis y una cepa de $L$. cremoris inhibieron el crecimiento de $E$. coli y Pseudomonas aeruginosa (Yüksekdag et al., 2004). Estos autores también describieron una cepa de L. thermophilus activo contra P. aeruginosa. Atanassova et al. (1999) y Santos et al. (2003) describieron una bacteriocina producida por una cepa clasificada como Lactobacillus spp. con actividad contra Listeria innocua F. Un número de Lactobacillus spp. aislados a partir de kéfir manifestaron actividad antimicrobiana contra bacterias enteropatogénicas y afectaron la adhesión de Salmonella typhimurium a células Caco-2. Las bacteriocinas son producidas especialmente por lactococos y lactobacilos, se caracterizan por presentar una actividad bactericida dirigida hacia bacterias Gram positivas (Blackbum et al., 1989; Takahashi y Kawakami, 1999). En cambio, las bacterias Gram negativas son poco sensibles a estas sustancias debido a la constitución de su pared celular y membrana externa (Lopitz-Otsoa et al., 2006; Ray y Daeschel, 1992; Takahashi y Kawakami, 1999).

El presente trabajo resultó después de haber investigado microorganismos patógenos en kéfir desde 1998 al 2004. Primeramente se evaluó la presencia de microorganismos patógenos en kéfir de leche y de agua; y a posteriori se verificó el efecto bactericida del kéfir sobre Salmonella spp. (Anselmo et al., 2001) así como sobre otros microorganismos patógenos transmitidos por alimentos. El objetivo del presente estudio es evaluar el posible efecto inhibidor que puedan ejercer las bacterias lácticas, acéticas y levaduras presentes en kéfir de dos procedencias distintas sobre Bacillus cereus y Clostridium perfringens y, su supervivencia durante el tiempo de conservación bajo refrigeración.

\section{MATERIALES Y METODOS}

El estudio se llevó a cabo en el Laboratorio de Microbiología, Universidad Nacional de Luján, provincia de Buenos Aires, Argentina; durante los meses de febrero a setiembre de 2008. 


\section{Materiales}

Cultivo de Bacillus cereus, suministrado por el Laboratorio de Bacteriología, Facultad de Farmacia y Bioquímica, Universidad de Buenos Aires, Argentina.

Cultivo de Clostridium perfringens, cepa de origen clínico, Hospital Británico de Buenos Aires, Argentina.

Kéfir A: procedencia italiana.

Kéfir B: procedencia peruana.

\section{Definición de los sistemas}

Se conformaron ocho sistemas: kéfir $A+$ células vegetativas de $B$. cereus, kéfir $B+$ células vegetativas de $B$. cereus, kéfir $A+$ células vegetativas de $C l$. perfringens, kéfir $B+$ células vegetativas de $C l$. perfringens, kéfir $A+$ endosporas de $B$. cereus, kéfir $B+$ endosporas de $B$. cereus, kéfir $\mathrm{A}+$ endosporas de $\mathrm{Cl}$. perfringens, kéfir $\mathrm{B}+$ endosporas de $\mathrm{Cl}$. perfringens. El resumen de los sistemas se pueden observar en la tabla 1.

\section{Inoculación de los sistemas}

Durante tres ocasiones diferentes, se preparó una suspensión de aproximadamente $10^{8} \mathrm{UFC} / \mathrm{mL}$ de Bacillus cereus y otra de Clostridium perfringens. Se utilizó $10 \mathrm{~mL}$ de esas suspensiones para inocular, respectivamente, $1 \mathrm{~L}$ de kéfir de cada una de las 2 distintas procedencias a estuadiar, es decir una carga inicial de $10^{6} \mathrm{UFC} / \mathrm{mL}$ de cada microorganismo patógeno a evaluar. Se conservó cada sistema a $4^{\circ} \mathrm{C}$ durante 30 días.

Tabla 1: Diferentes tratamientos según el sistema empleado

\begin{tabular}{|c|c|c|}
\hline Sistema & kéfir & Bacteria patógena \\
\hline 1 & A & células vegetativas de B. cereus \\
\hline 2 & A & células vegetativas de Cl. perfringens \\
\hline 3 & B & células vegetativas de $B$. cereus \\
\hline 4 & B & células vegetativas de Cl. perfringens \\
\hline 5 & A & endosporas de B. cereus \\
\hline 6 & A & endosporas de Cl. perfringens \\
\hline 7 & B & endosporas de B. cereus \\
\hline 8 & B & endosporas de Cl. perfringens \\
\hline
\end{tabular}

Medición de las poblaciones

Las poblaciones iniciales de bacterias lácticas, levaduras, $B$. cereus y $\mathrm{Cl}$. perfringens fueron medidas por recuento total (UFC/mL) en cada uno de los sistemas mencionados y luego se verificaron estas poblaciones durante 30 días o hasta la desaparición del patógeno agregado, haciendo mediciones cada 48 horas. Se utilizó la técnica de recuento total (UFC/g) para las bacterias lácticas y para las levaduras; mientras que para las bacterias patógenas se aplicaron las técnicas de recuento total (UFC/mL) en placa y el Número Más Probable $(\mathrm{NMP} / \mathrm{mL})$, utilizando series de tres tubos por dilución. Al mismo tiempo, durante los 30 días se determinaron las variaciones de $\mathrm{pH}$ utilizando un potenciómetro. Todos los medios de cultivo para bacterias fueron complementados con $200 \mathrm{mg} / \mathrm{L}$ de cicloheximida para inhibir el crecimiento de levaduras (Irigoyen et al., 2005). 


\section{Recuento total de Lactobacilos}

Se realizó tomando alícuotas de $10 \mathrm{~mL}$ de kéfir y se colocó en $90 \mathrm{~mL}$ de agua peptonada al $0,1 \%$ estéril $\left(10^{-1}\right)$. A partir de esta dilución se hicieron diluciones consecutivas decimales hasta $10^{-5}$ que se inocularon en agar de Man, Rogosa y Sharpe $(\mathrm{pH} 6,5 \pm 0,2)$ (Difco) por siembra de $1 \mathrm{~mL}$ de cada dilución por duplicado, en profundidad y sobrecapa del mismo medio de cultivo e incubación microaerófila $\left(5 \%\right.$ de $\left.\mathrm{CO}_{2}\right)$ a $30^{\circ} \mathrm{C}$ durante 72 horas, según el procedimiento para la determinación de bacterias lácticas descrito por Vanderzant y Splittstoesser, 1995.

\section{Recuento total de Lactococos}

Se realizó utilizando las diluciones descritas anteriormente las cuales se inocularon en medio M17

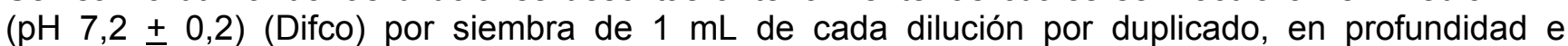
incubación aeróbica a $30^{\circ} \mathrm{C}$ por 48 horas.

\section{Recuento total de levaduras}

Se realizó utilizando las diluciones descritas anteriormente las cuales se inocularon en medio glucosa-extracto de levadura con $100 \mathrm{mg}$ de oxitetraciclina/L de medio ( $\mathrm{pH} 7,0 \pm 0,2)$ (Difco) por siembra de $0,1 \mathrm{~mL}$ de cada dilución por duplicado, en superficie e incubación aeróbica a $25^{\circ} \mathrm{C}$ por 72 horas.

\section{Recuento total de B. cereus}

Se realizó utilizando las diluciones descritas anteriormente las cuales se inocularon en agar manitol-

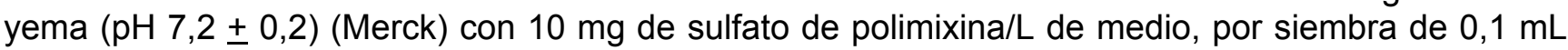
de cada dilución por duplicado, en superficie e incubación a $30^{\circ} \mathrm{C}$ por $24-48$ horas. Para el recuento de endosporas las diluciones previamente se sometieron a $80^{\circ} \mathrm{C}$ durante 10 min en baño maría.

NMP de B. cereus

Se realizó utilizando las diluciones descritas anteriormente las cuales se inocularon en series de 3

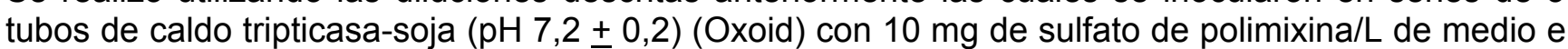
incubación a $30^{\circ} \mathrm{C}$ por 48 horas (fase de enriquecimiento). Los tubos positivos por turbidez y

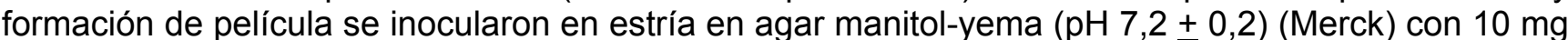
de sulfato de polimixina/L de medio, e incubación a $30^{\circ} \mathrm{C}$ por $24-48$ horas (fase selectiva). Para el recuento de endosporas las diluciones previamente se sometieron a $80^{\circ} \mathrm{C}$ durante 10 min en baño maría.

\section{Recuento total de Cl. perfringens}

Se realizó utilizando las diluciones descritas anteriormente las cuales se inocularon en agar sulfito-

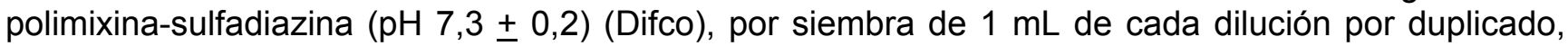
en profundidad y sobrecapa del mismo medio de cultivo, e incubación en jarra anaeróbica (Oxoid) a $35^{\circ} \mathrm{C}$ por 24 horas. Para el recuento de endosporas las diluciones previamente se sometieron a $80^{\circ} \mathrm{C}$ durante 10 min en baño maría.

\section{NMP de Cl. perfringens}

Se realizó utilizando las diluciones descritas anteriormente las cuales se inocularon en series de 3 tubos de medio reforzado para clostridios $(\mathrm{pH} 6,8 \pm 0,2)$ (Difco) con $10 \mathrm{mg}$ de sulfato de polimixina/L de medio e incubación a $35^{\circ} \mathrm{C}$ por 24 horas (fase de enriquecimiento). Los tubos positivos por turbidez fueron inoculados en agar sulfito-polimixina-sulfadiazina (Difco), por siembra en profundidad y sobrecapa del mismo medio de cultivo, e incubación en jarra anaeróbica Oxoid a $35^{\circ} \mathrm{C}$ por 24 horas (fase selectiva). Para el recuento de endosporas las diluciones previamente se sometieron a $80^{\circ} \mathrm{C}$ durante 10 min en baño maría. 


\section{RESULTADOS}

La población de bacterias lácticas y de levaduras permaneció en $10^{8}$ y $10^{6} \mathrm{UFC} / \mathrm{mL}$ respectivamente durante las mediciones, mientras que el pH se mantuvo entre 3,6 y 4,1.

En la figura 1 se describe el comportamiento de las células vegetativas y endosporas de $B$. cereus inoculado en los kefires A y B. Para el sistema 1, (kéfir A inoculado con B. cereus), la desaparición de células vegetativas se dio al décimo segundo día. Para el sistema 3 (kéfir $B$ inoculado con $B$. cereus), la desaparición de células vegetativas no se dio hasta el día 14 de almacenamiento. Para el sistema 5, (kéfir A inoculado con B. cereus), la desaparición de endosporas se dio al décimo sexto día. Para el sistema 7 (kéfir B inoculado con B. cereus), la desaparición de endosporas no se dio hasta el día 20 de almacenamiento.

En la figura 2 se describe el comportamiento de las células vegetativas y endosporas de $\mathrm{Cl}$. perfringens inoculado en los kefires A y B. Para el sistema 2, (kéfir A inoculado con Cl. perfringens), la desaparición de células vegetativas se dio al décimo segundo día de almacenamiento. Para el sistema 4 (kéfir $\mathrm{B}$ inoculado con $\mathrm{Cl}$. perfringens), no hubo detección de sus células vegetativas en el día décimo cuarto de almacenamiento. Para el sistema 6, (kéfir A inoculado con $\mathrm{Cl}$. perfringens), la desaparición de endosporas se dio al décimo cuarto día de almacenamiento. Para el sistema 8 (kéfir $\mathrm{B}$ inoculado con $\mathrm{Cl}$. perfringens), no hubo detección de sus endosporas en el día décimo octavo de almacenamiento.

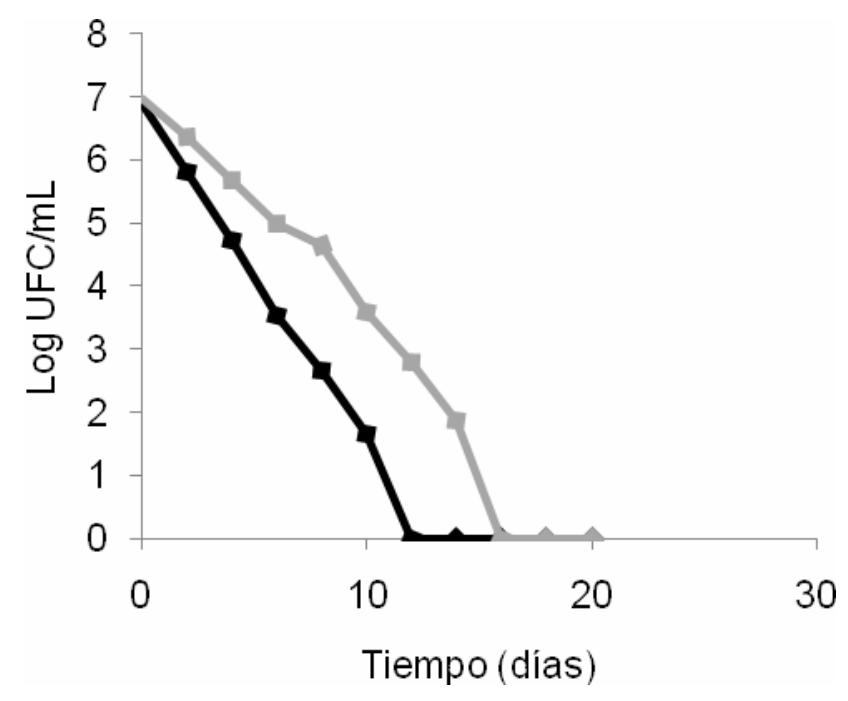

(a)

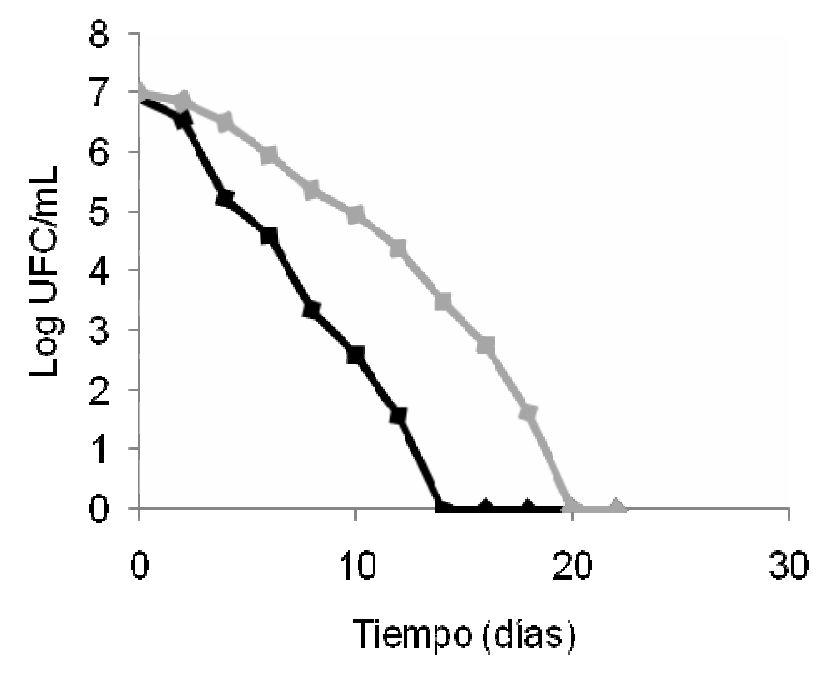

(b)

Fig. 1: Comportamiento de Bacillus cereus en kéfir en función del tiempo (一- células vegetativas, - - - endosporas, a) en kéfir $A, b)$ en kéfir B)

\section{DISCUSIÓN}

Se han atribuido al kéfir muchos beneficios sobre la salud, incluyendo sus "actividades antimicrobianas contra un rango de bacterias Gram positivas, Gram negativas y hongos. En pruebas realizadas in vitro con extractos libres de células de kéfir, el crecimiento de Staphylococcus aureus, Bacillus cereus, Escherichia coli, Clostridium perfringens y Listeria monocytogenes fueron inhibidos" (Van Wyk, 2001). En nuestro trabajo esta acción es constatada al evaluar cada sistema de kéfir inoculado a través del tiempo, los cuales presentaron una disminución en la población de los microorganismos patógenos agregados. Además puede observarse que $\mathrm{Cl}$. perfringens fue más susceptible que $B$. cereus debido a que el primero sobrevivió 16 días a $4^{\circ} \mathrm{C}$ mientras que el segundo hasta 18 días. 
Los niveles necesarios para que las bacterias probióticas ejerzan su acción contra las bacterias patógenas in vivo dependen de la dosis mínima por porción de $2 \times 10^{6}$ bacterias $/ \mathrm{mL}$ las cuales al llegar al sistema digestivo se verán afectadas por una acidez estomacal de rango menores a los que estas bacterias toleran, sin embargo, se ha encontrado que pueden liberar sustancias al medio logrando un efecto tampón de los alrededores, aumentando el $\mathrm{pH}$ y manteniendo su supervivencia (Jack et al, 1995). En nuestro estudio durante todas las mediciones se superó en dos potencias la cifra mencionada precedentemente en lo que respecta a las bacterias lácticas.

El descenso en el $\mathrm{pH}$ del medio es considerado como un factor importante para controlar el crecimiento de patógenos, pues muchos se ven inhibidos a pH bajos. $B$. cereus es una bacteria que ha demostrado, en diversos estudios, su resistencia tanto a pH ácido, así como su capacidad de multiplicación a bajas temperaturas. Estudios efectuados con $B$. cereus revelan que éste puede crecer en un ámbito de $\mathrm{pH}$ entre 4,9 y 9,3 , siendo su pH óptimo de crecimiento alrededor de 7,0 . En cuanto al rango de temperatura de crecimiento va desde 5 a $50^{\circ} \mathrm{C}$, siendo su óptima temperatura de crecimiento de $30-35^{\circ} \mathrm{C}$. Cl. perfringens presenta un rango de temperaturas de crecimiento comprendido entre 15 y $50^{\circ} \mathrm{C}$ con una temperatura óptima de $43-47^{\circ} \mathrm{C}$, mientras que el rango de $\mathrm{pH}$ va desde 5,5 a 8,0 .

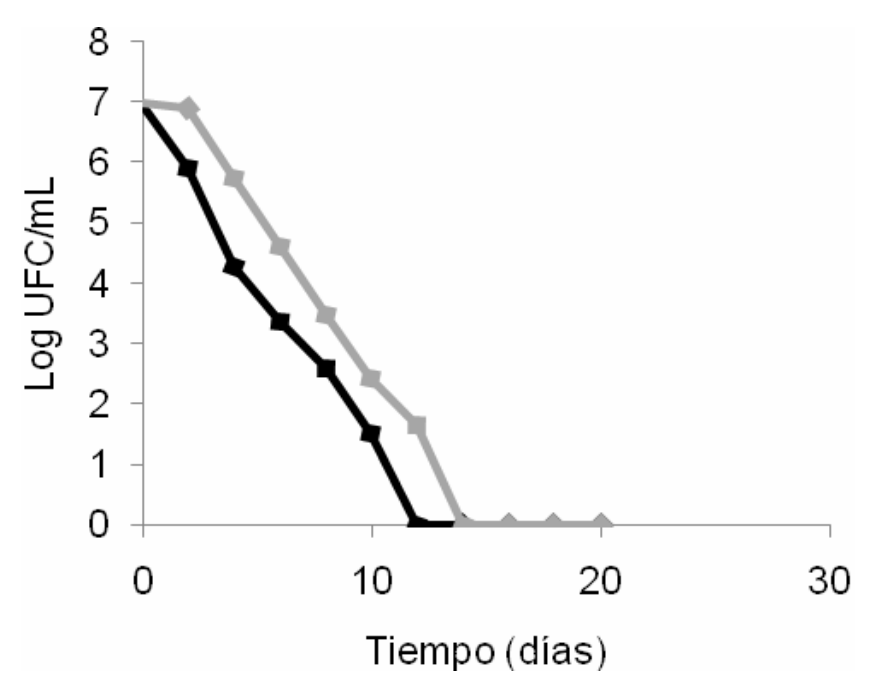

(a)

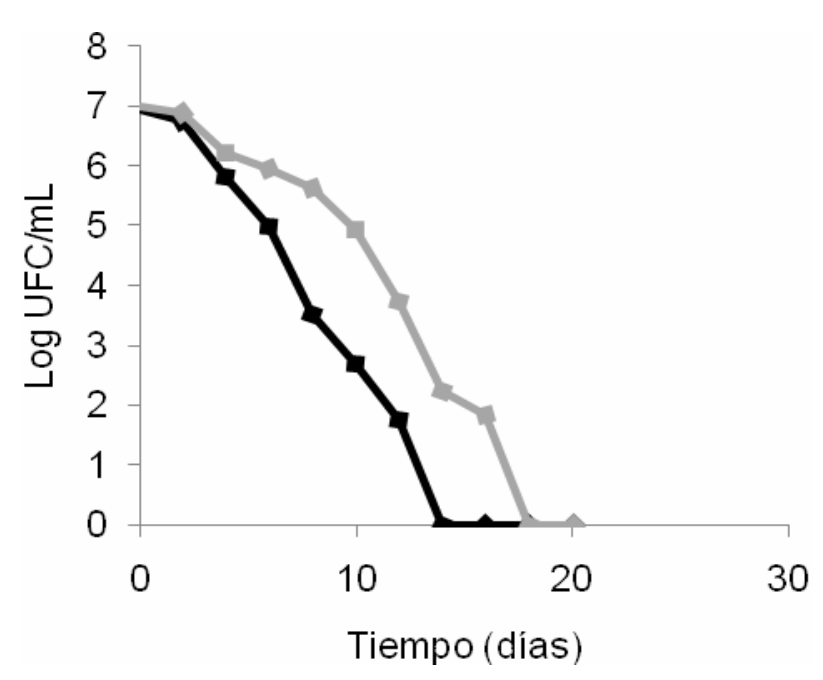

(b)

Fig. 2: Comportamiento de Clostridium perfringens en kéfir en función del tiempo (-ם- células vegetativas, - - - endosporas, a) en kéfir $A, b)$ en kéfir B)

\section{CONCLUSIONES}

De los resultados y de su análisis presentado en la sección anterior se puede obtener las siguientes conclusiones: i) ambos kéfires son eficientes en la inhibición in vitro de las bacterias patógenas estudiadas, ii) las ínfimas diferencias obtenidas según la procedencia de los kéfires podría atribuirse a la variación de la flora constituyente de los granos de kéfir y iii) las endosporas de $B$. cereus y $\mathrm{Cl}$. perfringens sobreviven hasta 18 y 16 días a $4^{\circ} \mathrm{C}$ respectivamente.

En este trabajo se comprobó que estas bacterias patógenas pueden sobrevivir al bajo pH y a las temperaturas de refrigeración por un tiempo significativo, existiendo la posibilidad de que si contaminaran productos lácteos después de la pasteurización, podrían sobrevivir el tiempo necesario para infectar a alguna persona. Esto resalta la importancia de un buen manejo durante la producción y almacenamiento del kéfir. 


\section{AGRADECIMIENTOS}

A la Universidad Nacional de Luján y al Departamento de Ciencias Básicas por el apoyo recibido para la ejecución del proyecto.

\section{REFERENCIAS}

Anselmo, R. J., S. Viora y L. I. Lausada, Efecto bactericida del kéfir sobre Salmonella spp., Rev. Información Tecnológica, Chile, 12 (5) 91-96 (2001).

Attanasova, M., y otros cuatro autores, Microbiologial study of kefir grains. Isolation and identification of high activity bacteriocin producing strains, Biotechnology and Biotechnological Equipment, 13: 5560 (1999).

Blackburn, P., J. Polar, A. Gusik y D. Rubing, Nisin composition for the use as enhanced broad range bactericides, International Patent Application publication WO 89112399 (1989).

Golowczyc, M., G. Garrote, A. G. Abraham y G. L. De Antoni, Interacción de lactobacilos aislados del kéfir con Salmonella sp. sobre células CACO-2/T C7, XVII Congreso Latinoamericano de Microbiología. X Congreso Argentino de Microbiología, Trabajo L 617. Organizado por la Asociación Argentina de Microbiología. Buenos Aires, Argentina. 17 al 21 de oct. de 2004.

Havenaar, R., B. Brink y J. H. J. Huis in't Veld, Selection of strains for probiotic use, In R. Fuller (Ed.), Probiotics, the scientific basis. London, UK: Chapman \& Hall (pp. 209-224) (1992).

Helander, I. M., A. Von Wright y T. M. Mattila-Sandholm, Potential of lactic acid bacteria and novel antimicrobials against gramnegative bacteria, Trends in Food Science and Technology I, 8: 146-150 (1997).

Irigoyen, A., y otros cuatro autores, Microbiological, physicochemical, and sensory characteristics of kefir during storage, Food Chemistry 90: 613-620 (2005).

Jack, R., J. Tagg y B. Ray, Bacteriocins of Gram positive bacteria, Microb, Rev. 59:171-200 (1995).

Kakisu, E., A. Abraham, P. Pérez y G. De Antoni, Acción inhibitoria del kéfir sobre Bacillus cereus, XVII Congreso Latinoamericano de Microbiología. X Congreso Argentino de Microbiología. Trabajo L 615. Organizado por la Asociación Argentina de Microbiología. Buenos Aires, Argentina. 17 al 21 de oct. de 2004.

Lopitz-Otsoa, F., A. Rementeria, N. Elguezabal y J. Garaizar, Kefir: A symbiotic Yeasts-bacteria community with alleged healthy capabilities, Rev. Iberoam. Micol. 23: 67-74 (2006).

Powell, J. E., R. C. Witthuhn, S. D. Todorov y L. M. T. Dicks, Characterization of bacteriocin ST8KF produced by a kéfir isolate Lactobacillus plantarum ST8KF, International Dairy Journal 17: 190-198 (2007).

Ray, B. y M. Daeschel, Food biopreservatives of microbiological origin, CRC press, Ing., Boca Ratón, Fla (1992).

Rodrigues, K. L., y otros cuatro autores, Antimicrobial and healing activity of kéfir and kefiran extract, International Journal of Antimicrobial Agents, 25: 404-408 (2005).

Santos, A., y otros cuatro autores, The antimicrobial properties of different strains of Lactobacillus spp. isolated from Kefir, Systematic and Applied Microbiology, 26: 434-437 (2003).

Takahashi, F. y H. Kawakami, Antibacterial action of kefir againts Escherichia coli 0157:H7. Jpn. J. Food Microbiol. 16: 245-247 (1999). 
Tamime, A. Y., D. D. Muir y M. Wszolek, Kefir, Koumiss and Kishk, Dairy Ind. Int. 65 (5) 32-33 (1999).

Vanderzant, C. y D. Splittstoesser, Compendium of methods for the microbiological examination of foods, APHA. Washington DC. 553-590 (1995).

Van Wyk, J., The inhibitory activity and sensory properties of Kefir, targeting the low-income African consumer market. Masters thesis, Stellenbosch University, Stellenbosch, South Africa (2001).

Yüksekdag, Z. N., Y. Beyatli y B. Aslim, Determination of some characteristics coccoid forms of lactic acid bacteria isolated from Turkish kefirs with natural probiotic, Lebensmittel Wissenschaft und Tech. 37: 663-667 (2004). 